\title{
Effects of Temperature Variability and Warming on the Timing of Snowmelt Events in Southern Finland during the Past 100 Years
}

\author{
Masoud Irannezhad* \\ School of Environmental Science and Engineering, Southern University of Science and Technology, Shenzhen, \\ Guangdong, China
}

*Corresponding author: irannezhad@sustech.edu.cn

\begin{abstract}
This study analyses the first and last days of snowmelt events and the number of days (duration) between those throughout a water year (September-August). The snowmelt duration (SD) as well as its first (SFD) and last (SLD) days were estimated using daily precipitation and temperature measurements at the Kaisaniemi meteorological station in southern Finland during 1909-2008 as input datasets to a temperature-index snowmelt model. As snowmelt is a sensitive hydrological variable to temperature, this study also evaluated historical variations and trends in November-May (SDt), November-January (SFDt), and March-May (SLDt) temperatures corresponding to SD, SFD, and SLD at Kaisaniemi. The trends in all these parameters as well as their correlations with the well-known climate teleconnections over Finland were investigated. Long-term average values indicated the longest SD was about 131 days between 15 December and 25 April at Kaisaniemi. The SD significantly $(\mathrm{p}<0.05)$ shortened by 0.37 (days/year) at Kaisaniemi during 1909-2008 mainly due to the earlier (0.32 days/year) SLD. Such trends in SD and SLD were principally associated with century-long significant warming trends $\left(0.02{ }^{\circ} \mathrm{C} /\right.$ year $)$ in both SDt and SLDt. The Arctic Oscillation (AO) was the most influential climate teleconnection for historical variations in SD, SLD, SDt, SFDt, and SLDt at Kaisaniemi.
\end{abstract}

Keywords: duration; first and last days; Kaisaniemi; trend analysis; snowpack hydrological processes; temperature-index model; climate teleconnections.

\section{Introduction}

In the boreal environment of Finland, snow plays a crucial role in land surface hydrology by storing water during cold months and releasing it gradually as snowmelt into rivers through the spring and early summer (Mote et al., 2005). Such snowmelt typically generates the major volume contribution to peak annual discharge in rivers and provides water resources required for different human activities (e.g. forestry, agriculture, recreation, and energy) as well as both aquatic and terrestrial ecosystems (Wilson et al., 2010). Altering temporal characteristics of snowmelt events (Pohl et al., 2007), climate change significantly impacts the water resources and consequently natural environment throughout the Nordic countries (Barnett et al., 2005). More frequent snowmelt floods in wintertime, spring groundwater level depletion, less summertime base flow, and on the timing of snowmelt events (Barnett et al., 2008; Okkonen and Kløve, 2010). In general,

Copyright (C) 2019 by author(s) and Frontier Scientific Research Publishing Inc.

This work is licensed under the Creative Commons Attribution International License (CC BY 4.0).

http://creativecommons.org/licenses/by/4.0/ 
such variations in regional and/or local temperatures are controlled by large-scale climate teleconnections, e.g. the North Atlantic Oscillation (NAO), which are defined as persistent, repetitive, and large modes of pressure anomaly centers representing the main airflow over a particular geographical region during a specific period of the year (Chen and Chen, 2003; Glantz et al., 2009).

This study aims at understanding the influences of large-scale climate signals on the shifts in snowmelt timing at the Kaisaniemi meteorological station in southern Finland. The main objectives are to: (1) detect statistically significant trends in the timing of snowmelt events at Kaisaniemi during 1909-2008; (2) identify the role of temperature warming in such trends; (3) measure the correlations of the timing of snowmelt events with temperature and a number of well-known large-scale climate teleconnections.

\section{Material and Methods}

\subsection{Study area and data description}

With the boreal climate, Finland extends about $1320 \mathrm{~km}$ in the south-north direction of northern Europe (Figure 1a). Hence, the country experiences a strong latitudinal gradient in temperature, particularly during winter, which significantly influences snow accumulation and melt processes. Both annual mean temperature and total precipitation naturally decrease from south to north throughout Finland (Figure 1b and c). Long-term (1911-2011) average values for annual mean temperature and total precipitation are $1.7^{\circ} \mathrm{C}$ (Mikkonen et al., 2015) and $601 \mathrm{~mm}$ (Irannezhad et al., 2014) respectively. Snow cover duration is typically $<130$ days in southern Finland, but $>205$ days in northern areas (Pirinen et al., 2012).

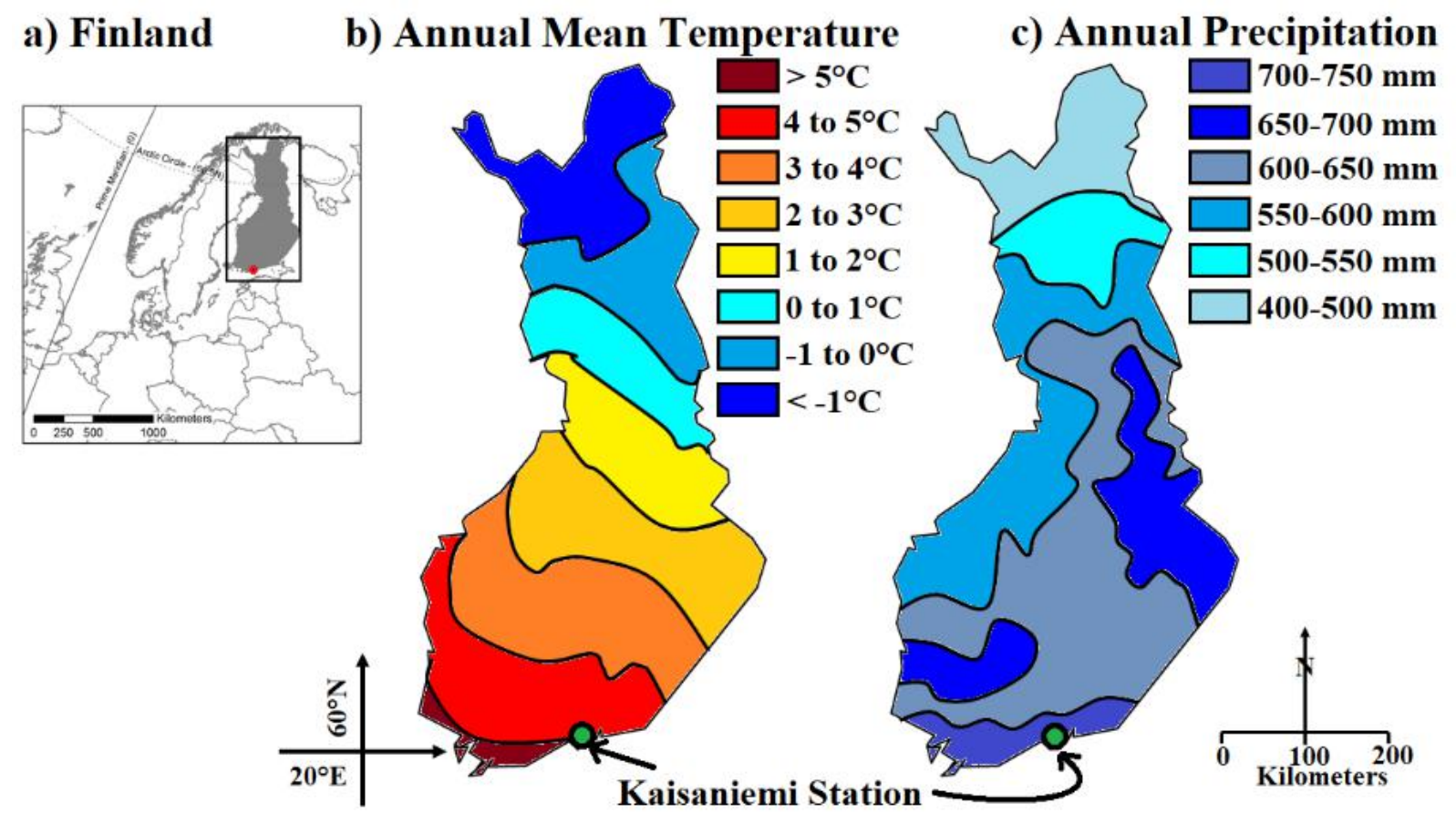

Figure 1. a) Map of northern Europe with Finland colored gray and maps showing the location of Kaisaniemi meteorological station in Finland and long-term (1981-2010) average values of; b) annual mean temperature $\left.\left({ }^{\circ} \mathrm{C}\right) ; \mathrm{c}\right)$ annual precipitation (mm). Compiled based on Pirinen et al. (2012).

For this study, the Kaisaniemi meteorological station of the Finnish Meteorological Institute (FMI) in southern Finland (Figure 1) was used because: (1) it has daily temperature and precipitation records covering 1909-2008, with no missing data; (2) it is located in the maritime snow cover class (Sturm et al., 1995); (3) it includes homogenous precipitation time series adjusted by Irannezhad et al. (2016a); (4) it previously employed by other studies related to snow 
hydrology in Finland (e.g.Irannehzad et al., 2017). This station (Kasianiemi) is geographically located at $60.18^{\circ} \mathrm{N}$ and $24.94^{\circ} \mathrm{E}$ (Helsinki city center), with an altitude of $4 \mathrm{~m}$ above the mean sea level. During 1909-2008, long-term average values for annual mean temperature and total precipitation were $5.2^{\circ} \mathrm{C}$ and $821 \mathrm{~mm}$ respectively. The annual continuous possible snow cover (snow water equivalent $>0 \mathrm{~mm}$ ) duration was about 182 days at the Kaisaniemi station during 1909-2008 (Irannezhad et al., 2016b).

Daily adjusted precipitation and mean temperature at the Kaisaniemi station during the period 1909-2008 were used as input to the calibrated and validated temperature-index snowmelt model (Irannezhad et al., 2015a) to simulate different snowpack accumulation and melt processes in southern Finland. Accordingly, all snowmelt events in each water year (September to the following August) at Kaisaniemi during 1909-2008 were identified. This study, hence, defined the snowmelt duration (SD) as the number of days between the first (SFD) and last (SLD) snowmelt days during each water year from 1909 to 2008. As snowmelt is highly sensitive to temperature, this study also investigated changes in November-May (SDt), November-January (SFDt), and March-May (SLDt) mean temperatures at Kaisaniemi corresponding to the SD, SFD, and SLD respectively.

Based on previous studies (Irannezhad et al., 2014; Irannezhad et al., 2015), six large-scale climate teleconnections naturally influence variations in precipitation and temperature across Finland. These climate teleconnections are the Arctic Oscillation (AO), East Atlantic (EA), East Atlantic/West Russia (EA/WR), North Atlantic Oscillation (NAO), Polar/Eurasian (Polar) pattern, and Scandinavia (SCA) pattern. For all these climate teleconnections, the Climate Prediction Center (CPC) at the National Oceanic and Atmospheric Administration (NOAA) in the USA (http://www.cpc.ncep.noaa.gov/data/teledoc/telecontents.shtml) calculates the standardized monthly values from January 1950. This study, hence, calculates the average of standardized monthly values for November-May, November-January, and March-May during the water year (September-August) corresponding to the SD, SFD, and SLD respectively.

\subsection{Statistical methods}

To detect statistically significant $(\mathrm{p}<0.05)$ trends, this study applied the Mann-Kendall non-parametric test $($ Mann, 1945; Kendall, 1975). The slope of such detected significant trends was calculated employing the Sen (Sen, 1968) method. The 95\% confidence intervals for these slopes were computed to estimate the uncertainties with significant trends (Helsel and Hirsch, 1992). Besides, the relationships of SD, SFD, and SLD with their corresponding temperatures (SDt, SFDt, and SLDt) and climate teleconnections were measured using the Spearman's rank correlation (rho) (Helsel and Hirsch, 1992).

\section{Results and Discussion}

At Kaisaniemi, long-term (1909-2008) average values for the snowmelt duration (SD) as well as its first (SFD) and last (SLD) days were about 131, 106 (15 December), and 237 (25 April) respectively (Figure 2). During 1909-2008, the SD showed a statistically significant $(\mathrm{p}<0.05)$ shortening trend at the rate of $0.37 \pm 0.18$ (days/year) (Figure $2 a)$ that was primarily contributed by the substantially earlier SLD (0.32 \pm 0.08 days/year) (Figure 2c). Such decreases in SD and SLD were principally associated with significant warming trends in SDt $\left(0.018 \pm 0.009{ }^{\circ} \mathrm{C} /\right.$ year $)$ and $\mathrm{SLDt}\left(0.020 \pm 0.008{ }^{\circ} \mathrm{C} / \mathrm{year}\right)$ at the Kaisaniemi station over the period 1909-2008 respectively (Figure 3a and c). Although there was a statistically significant increasing trend in the SFDt $\left(0.015 \pm 0.013^{\circ} \mathrm{C} /\right.$ year) at Kaisaniemi in 1909-2008 (Figure 3b), no clear changes in historical SFD were found at this station (Figure 2b). This can be explained by relatively weaker significant correlations between SFDt and SDF (rho = -0.20) than that between SDt and SD (rho= -0.32) as well as between SLDt and SLD (rho $=-0.79$ ) (Figure 4).

All SDt, SFDt, and SLDt at the Kaisaniemi station in southern Finland showed the most significant correlations with the Arctic Oscillation (AO), with the rho $=0.68,0.51$, and 0.49 respectively (Figure 3 ). The AO was also the most 
influential climate teleconnection for interannual variations in both SD (rho $=-0.35)$ and SLD (rho $=-0.35)$, while no clear relationships were found between the SFD and the large-scale climate teleconnections (Figure 2). Similarly, the North Atlantic Oscillation (NAO) showed significant positive correlations with all SDt, SFDt, and SLDt (rho ranged between 0.32 and 0.58 ) at the Kaisaniemi station, while negative correlations with both SD (rho $=-0.25$ ) and SLD (rho $=-0.28$ ) (Table 1). Other significant relationships of climate teleconnections with the timing of snowmelt events and their corresponding temperatures are given in Table 1 .

(a)

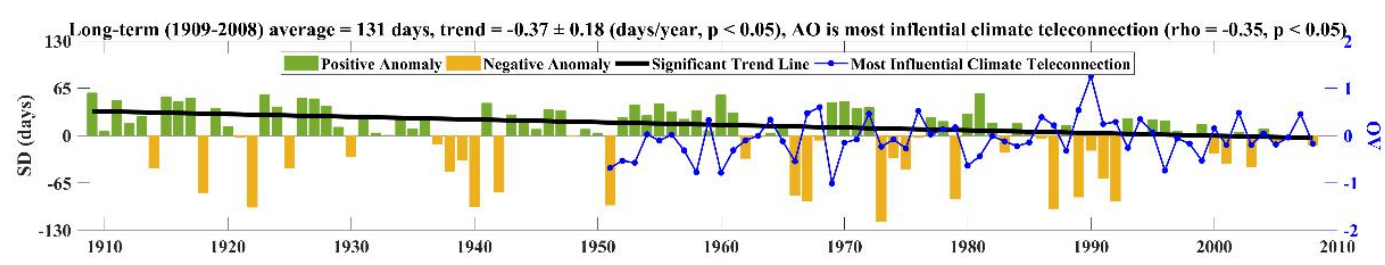

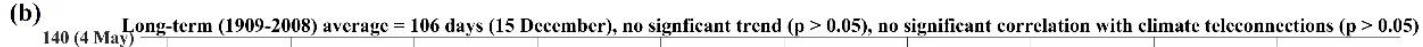

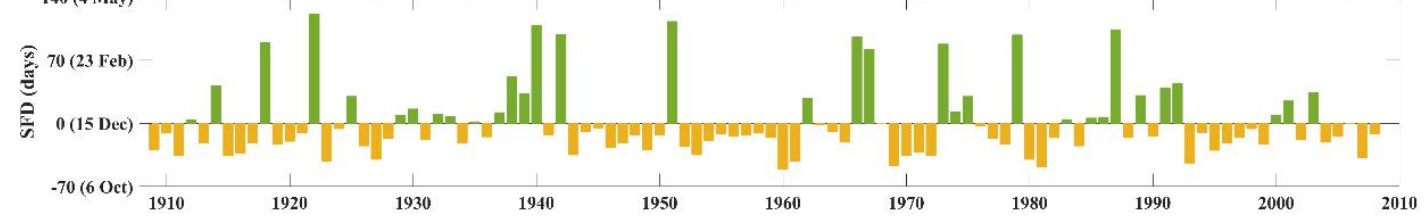

(c) 60 (249ng-term (1909-2008) average $=237$ days (25 April), trend $=-0.32 \pm 0.08$ (days/year, $p<0.05)$, AO is most inflential climate teleconnection (rho $=-0.35, p<0.05)$

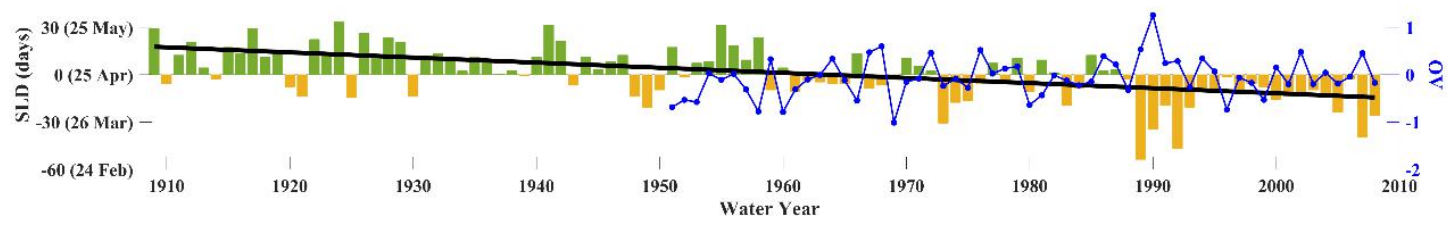

Figure 2. Anomalies with significant trend line $(\mathrm{p}<0.05)$ and the most influential climate teleconnection for annual (a) snowmelt duration (SD) as well as its (b) first (SFD) and (c) last (SLD) day at the Kaisaniemi station in southern

Finland during the water years (September-August) 1909-2008.

Table 1. Spearman's rank correlation (rho) values for snowmelt duration (SD), its first (SFD) and last (SLD) days as well as their corresponding temperatures (SDt, SFDt, and SLDt, respectively) at the Kaisaniemi station in southern Finland, relative to climate teleconnections influencing precipitation and temperature variability across Finland, during 1951-2008. In bold type if $\mathrm{p}<0.05$.

\begin{tabular}{|c|c|c|c|c|c|c|c|}
\hline \multirow[t]{2}{*}{ Variable } & \multirow[t]{2}{*}{ Indicator } & \multicolumn{6}{|c|}{ Climate Teleconnection } \\
\hline & & AO & EA & EA/WR & NAO & POL & SCA \\
\hline \multirow{3}{*}{ Snowmelt } & SD & -0.35 & -0.32 & -0.01 & -0.25 & -0.07 & 0.14 \\
\hline & SFD & 0.06 & 0.04 & 0.08 & 0.02 & 0.01 & 0.06 \\
\hline & SLD & -0.35 & -0.27 & 0.11 & -0.28 & -0.10 & 0.15 \\
\hline \multirow{3}{*}{$\begin{array}{l}\text { Corresponding } \\
\text { Temperature }\end{array}$} & SDt & 0.68 & 0.23 & 0.10 & 0.53 & -0.12 & -0.42 \\
\hline & SFDt & 0.51 & 0.16 & 0.15 & 0.42 & -0.06 & -0.06 \\
\hline & SLDt & 0.49 & 0.28 & -0.21 & 0.32 & 0.08 & -0.18 \\
\hline
\end{tabular}


(a)

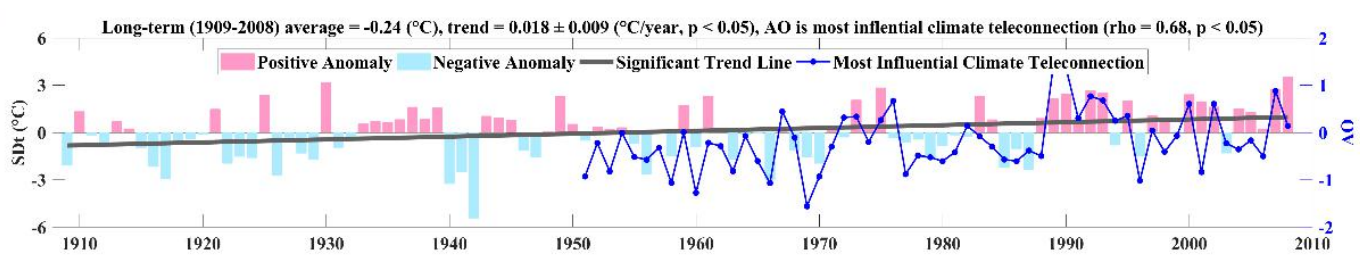

(b)

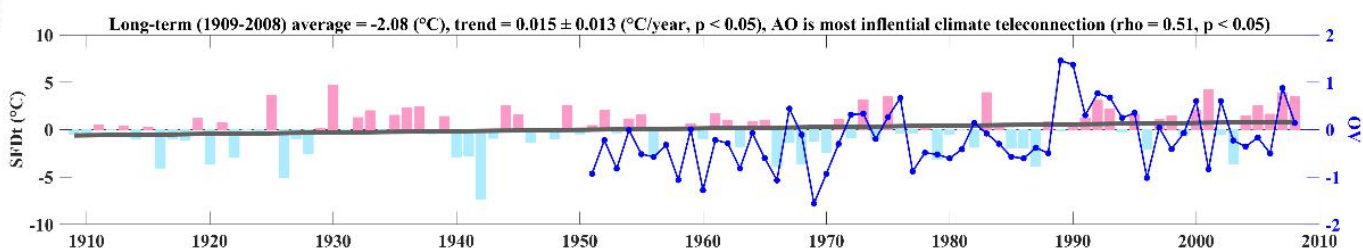

(c)

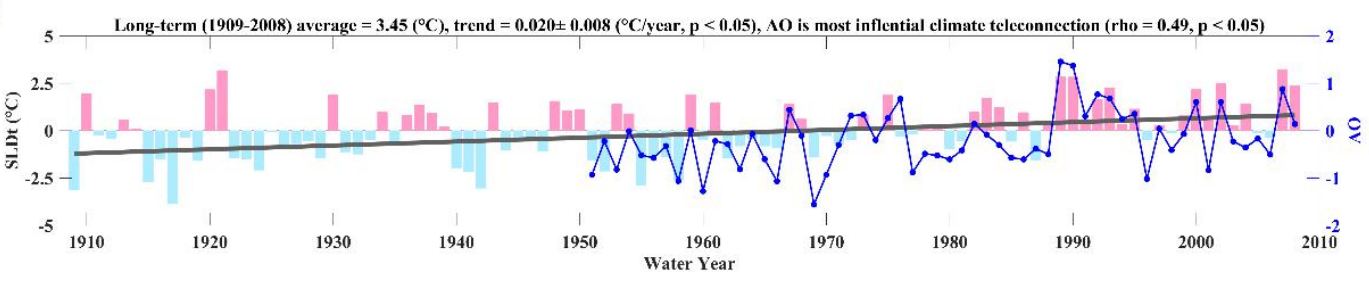

Figure 3. Anomalies with significant trend line $(\mathrm{p}<0.05)$ and the most influential climate teleconnection for annual (a) SDt, (b) SFDt, and (c) SLDt at the Kaisaniemi station in southern Finland for the water years (September-August) 1909-2008.
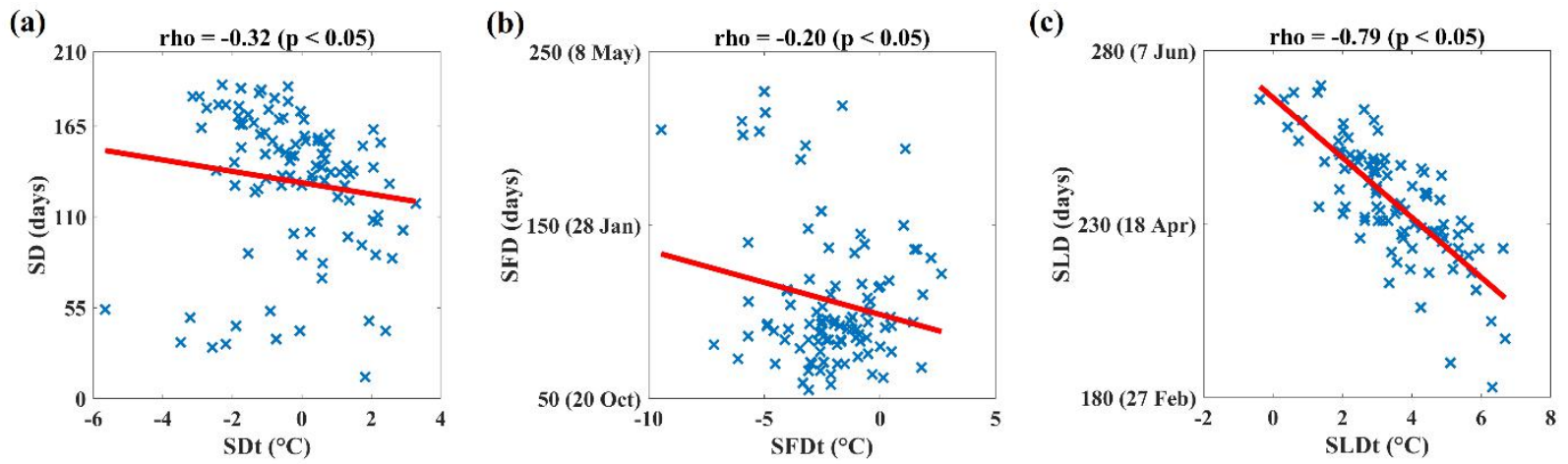

Figure 4. Correlations between annual (a) SDt and SD, (b) SFDt and SFD, and (c) SLDt and SLD, at the Kaisaniemi station in southern Finland during the water years (September-August) 1909-2008.

The AO describes the power of circumpolar vortex (Thompson and Wallace, 1998), and the NAO indicates the strength of westerlies from the North Atlantic to the Atlantic sector of Europe (Hurrell, 1995). Accordingly, the positive values of AO and NAO are associated with mild (warm) and wet maritime airflow over northern Europe, especially during the cold months of the year. Besdies, Serreze et al. (2000) concluded that the NAO could be considered as the key component of the AO. Many previous studies reported that substantial increases in the values of both AO and NAO from 1950 (Wang et al., 2005) can basically explain the warming trend in temperature across the Northern Hemisphere, particularly during March (Jaagus, 2006; Irannezhad et al., 2015b). Such natural effects of both AO and NAO on temperature over the Fenno-Scandinavian region of northern Europe were also reflected by the results from this study.

Previous studies concluded that a significant shortening trend in historical continuous snow cover duration (CSCD) at the Kaisaniemi station in southern Finland was mainly due to the warmer temperatures accompanying with the positive 
phase of AO (Irannezhad et al., 2016b). Such shorter CSCD was mainly associated with the substantially earlier CSCD's end day (or snowmelt events) in response to the warmer spring temperatures. Irannezhad et al. (2017) also reported decreases in annual snowfall to total precipitation ratio $(\mathrm{S} / \mathrm{P})$ at Kaisaniemi because of warmer snowfall-day temperatures under the AO positive phases. Such declines in the annual S/P ratio can indirectly cause snowmelt duration (SD) to shortened as less snowfall decreases the expansion and thickness of snow cover and thereby shifts the last day of CSCD towards earlier in spring. Hence, the findings by the present study regarding shorter snowmelt duration (SD) and its earlier last day (SLD) due to warmer March-May (spring) temperatures (SLDt) were in agreement with previous studies. To obtain such results, however, this study focused on the timing of snowmelt events, while the previous papers analyzed CSCD and S/P ratio at Kaisaniemi in southern Finland.

\section{Conclusions}

During the past 100 years (1909-2008), the snowmelt duration (SD) substantially shortened by $37 \pm 18$ days at the Kaisaniemi station in southern Finland. This was primarily because of $32 \pm 8$ days earlier last days of snowmelt duration (SLD). The main driver for such changes was a significant warming trend in March-May (spring) temperature that strongly shifted the timing of snowmelt events toward earlier at Kaisaniemi during the water year. These warmer springs in southern Finland were positively associated with the Arctic Oscillation (AO), which also showed significant negative relationships with the SLD. Generally speaking, the AO played a critical role in warmer springs, earlier SLD, and consequently shorter SD at the Kaisaniemi station in southern Finland over time.

\section{Conflicts of Interest}

The author declares no conflicts of interest regarding the publication of this paper.

\section{Acknowledgments}

The author is grateful to the Finnish Meteorological Institute (FMI) and the Finnish Environment Institute (SYKE) for measuring and providing the hydrometeorological datasets for Finland. The Climate Prediction Center (CPC) at the National Oceanic and Atmospheric Administration (NOAA) of the US is also thanked for making openly available online the standardized monthly values of the climate teleconnections.

\section{References}

[1] Barnett, T.P., Pierce, D.W., Hidalgo, H.G., Bonfils, C., Santer, B.D., Das, T., Bala, G., Wood, A.W., Nozawa, T., Mirin, A.A., Cayan, D.R., Dettinger, M.D. (2008) Human-induced Changes in the Hydrology of the Western United States. Science, (319), 1080-1083.

[2] Barnett, T.P.T., Adam, J.C., Lettenmaier, D.P. (2005) Potential Impacts of a Warming Climate on Water Availability in Snow-dominated Regions. Nature, (438), 303-309.

[3] Chen, D., Chen, T. (2003) Association Between Winter Temperature in China and Upper Air Circulation over East Asia Revealed by Canonical Correlation Analysis. Glob. Planet. Chang, (37), 315-325.

[4] Glantz, M.H., Katz, R.W., Nicholls, N. (eds). (2009) Teleconnections Linking Worldwide Climate Anomalies: Scientific Basis and Societal Impact. Cambridge University Press, New York.

[5] Helsel, D.R., Hirsch, R.M. (1992) Statistical Methods in Water Resources. Studies in Environmental Science, Amsterdam, 522.

[6] Hurrell, J.W. (1995) Decadal Trends in the North Atlantic Oscillation: regional temperatures and precipitation. Science, (269), 676-679.

[7] Irannezhad, M., Chen, D., Kløve, B. (2015b). Interannual Variations and Trends in Surface Air Temperature in Finland in Relation to Atmospheric Circulation Patterns, 1961-2011. Int. J. Climatol., (35), 3078-3092. 
[8] Irannezhad, M., Marttila, H., Chen, D., Kløve, B. (2016a) Century-long Variability and Trends in Daily Precipitation Characteristics at Three Finnish Stations. Adv. Clim. Chang. Res., (7), 54-69.

[9] Irannezhad, M., Marttila, H., Kløve, B. (2014) Long-term Variations and Trends in Precipitation in Finland. Int. J. Climatol., (34), 3139-3153.

[10] Irannezhad, M., Ronkanen, A.-K., Kiani, S., Chen, D., Kløve, B. (2017) Long-term Variability and Trends in Annual Snowfall/Total Precipitation Ratio in Finland and the Role of Atmospheric Circulation Patterns. Cold Reg. Sci. Technol., (143), 23-31.

[11] Irannezhad, M., Ronkanen, A.-K., Kløve, B. (2015a) Effects of Climate Variability and Change on Snowpack Hydrological Processes in Finland. Cold Reg. Sci. Technol., (118), 14-29.

[12] Irannezhad, M., Ronkanen, A.-K., Kløve, B. (2016b) Wintertime Climate Factors Controlling Snow Resource Decline in Finland. Int. J. Climatol., (36), 110-131.

[13] Jaagus, J. (2006) Climatic Changes in Estonia during the Second Half of the 20th Century in Relationship with Changes in Large-scale Atmospheric Circulation. Theor. Appl. Climatol., (83), 77-88.

[14] Kendall, M.G. (1975) Rank Correlation Methods. Griffin, London.

[15] Mann, H.B. (1945) Nonparametric Tests against Trend. Econometrica, (13), 245-259.

[16] Mikkonen, S., Laine, M., Mäkelä, H.M., Gregow, H., Tuomenvirta, H., Lahtinen, M., Laaksonen, A. (2015) Trends in the Average Temperature in Finland, 1847-2013. Stoch. Env. Res. Risk A., (29), 1521-1529.

[17] Mote, P.W., Hamlet, A.F., Clark, M.P., Lettenmaier, D.P. (2005) Declining Mountain Snowpack in Western North America. Bull. Am. Meteorol. Soc., (86), 39-49.

[18] Okkonen, J., Kløve, B. (2010) A Conceptual and Statistical Approach for the Analysis of Climate Impact on Groundwater Table Fluctuation Patterns in Cold Conditions. J. Hydrol., (388), 1-12.

[19] Pirinen, P., Simola, H., Aalto, J., Kaukoranta, J.-P., Karlsson, P., Ruuhela, R. (2012) Tilastoja Suomen Ilmastosta 1981-2010 [Climatological statistics of Finland 1981-2010]. Reports 2012.1, Finnish Meteorological Institute, Helsinki (in Finnish and English).

[20] Pohl, S., Marsh, P., Bonsal, B.R. (2007) Modeling the Impact of Climate Change on Runoff and Annual Water Balance of an Arctic Headwater Basin. Arctic, (60), 173-186.

[21] Sen, P.K. (1968) Estimates of the Regression Coefficient Based on Kendall's tau. J. Am. Stat. Assoc., (63), 1379-1389.

[22] Serreze, M.C., Walsh, J.E., Chapin, F.S. III., Osterkamp, T., Dyurgerov, M., Romanovsky, V., Oechel, W.C., Morison, J., Zhang, T., Barry, R.G. (2000) Observational Evidence of Recent Change in the Northern High-latitude Environment. Clim. Change, (46), 159-207.

[23] Sturm, M., Holmgren, J., Liston, G.E. (1995) A Seasonal Snow Cover Classification System for Local to Global Applications. J. Clim., (8), 1261-1283.

[24] Thompson, D.W.J., Wallace, J. M. (1998) The Arctic Oscillation Signature in the Wintertime Geopotential Height and Temperature Fields. Geophys. Res. Lett., 25(9), 1297-1300.

[25] Wang, D., Wang, C., Yang, X., Lu, J. (2005) Winter Northern Hemisphere Surface Air Temperature Variability Associated with the Arctic Oscillation and North Atlantic Oscillation. Geophys. Res. Lett., (32), L16706.

[26] Wilson, D., Hisdal, H., Lawrence, D. (2010) Has Streamflow Changed in the Nordic Countries? - Recent Trends and Comparisons to Hydrological Projections. J. Hydrol., (394), 334-346. 